\title{
Efficient nitration of meso-tetraphenylporphyrin with nitronium tetrafluoroborate
}

\author{
Nicholas W. Smith and Sergei V. Dzyuba* \\ Department of Chemistry, Texas Christian University, Fort Worth TX 76129 \\ E-mail: s.dzyuba@tcu.edu
}

Dedicated to Professor Richard A. Bartsch on the occasion of his $70^{\text {th }}$ birthday

\begin{abstract}
Controllable and selective nitration of meso-tetraphenylporphyrin using nitronium tetrafluoroborate affords a chromatography-free access to mono-, bis- and tris(4-nitrophenyl)porphyrins in high yields.
\end{abstract}

Keywords: Porphyrin, nitration, regioselectivity

\section{Introduction}

Porphyrins are a versatile class of compounds with numerous applications in catalysis, biomimetics, photodynamic therapy, non-linear optics and molecular-based storage devices, among many others. ${ }^{1}$ Facile and versatile selective functionalization of readily available porphyrins will further increase the utility of porphyrins. Synthetic approaches to unsymmetrically functionalized porphyrins rely on either Rothermund or Lindsey's condensations, ${ }^{2}$ which are usually multi-step processes that require extensive separation steps. In this light, selective functionalization of easily accessible and commercially available mesotetraphenylporphyrin, TPP, (Figure 1) is highly desirable.

Nitration of TPP to produce nitro-porphyrins is attractive in view of facile conversion of the $\mathrm{NO}_{2}$-group into amino, nitroso and diazonium functionalities en route to elaborate porphyrincontaining scaffolds. ${ }^{3}$ Notably, porphyrins featuring electron-withdrawing substituents have also been shown to possess interesting and unusual properties. ${ }^{4}$ 

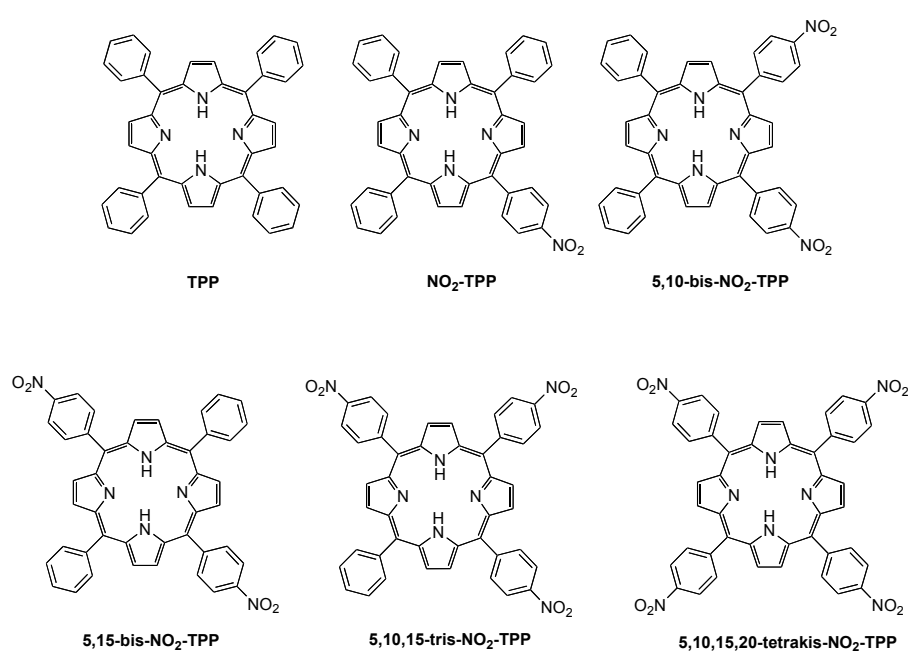

Figure 1. Structures and abbreviations of porphyrins.

Nitration of porphyrins has been evaluated using a variety of nitrating agents. ${ }^{5}$ Mononitration of TPP was reported to proceed smoothly with an excess of either red or yellow nitric acid; however, subsequent introduction of additional nitro-groups proved to be less efficient. ${ }^{6}$ In addition, in the presence of trifluoroacetic acid (TFA) - sodium nitrite, TPP was converted into a mixture of bis-nitrophenyl-porphyrins, i.e., 5,10-bis- $\mathrm{NO}_{2}$-TPP and 5,15-bis- $\mathrm{NO}_{2}$-TPP (Figure 1), which was directly subjected to the reduction with $\mathrm{SnCl}_{2}$ /acid, followed by a chromatographic separation to afford the corresponding diaminoporphyrins in moderate yields. ${ }^{7}$

Overall, the reported approaches rely on large excess of reagents, and usually lead to mixtures of nitrated products, which require either chromatographic separation or conversion to the corresponding amines, followed by chromatographic separation. Here we report on an efficient and selective preparation of nitro-porphyrins using $\left[\mathrm{NO}_{2}\right] \mathrm{BF}_{4}$ in sulfolane as a mild, easy to handle and selective nitrating agent.

\section{Results and Discussion}

$\left[\mathrm{NO}_{2}\right] \mathrm{BF}_{4}$ is a known nitrating reagent for various aromatic species. ${ }^{8}$ However, application of this reagent for nitration of porphyrins has received limited attention. Previous research demonstrated that $\left[\mathrm{NO}_{2}\right] \mathrm{BF}_{4}$ in sulfolane at elevated temperatures did not readily nitrate porphyrins. ${ }^{9}$ In pyridine, at high temperatures, $\left[\mathrm{NO}_{2}\right] \mathrm{BF}_{4}$ mediated the incorporation of a $\beta$ pyridinium moiety onto TPP scaffold. ${ }^{10}$

In our hands, a complex mixture was obtained when TPP was subjected to an excess of $\left[\mathrm{NO}_{2}\right] \mathrm{BF}_{4}$ at room temperature, whereas treatment of TPP with 1 equivalent of $\left[\mathrm{NO}_{2}\right] \mathrm{BF}_{4}$ at room temperature, did not induce any nitration, and TPP was recovered unchanged. However, when $\left[\mathrm{NO}_{2}\right] \mathrm{BF}_{4}$ was added sequentially, that is, the first equivalent was added drop-wise, the 
reaction was allowed to stir for several minutes, followed by a drop-wise addition of another equivalent of $\left[\mathrm{NO}_{2}\right] \mathrm{BF}_{4}$, a clean and quantitative conversion (based on TLC and ${ }^{1} \mathrm{H}$ NMR analysis of the crude mixture) of TPP to $\mathrm{NO}_{2}$-TPP was obtained (Scheme 1).

Encouraged by these results, we decided to explore the ability of $\left[\mathrm{NO}_{2}\right] \mathrm{BF}_{4}$ to produce a series of nitro substituted TPP analogues. This sequential addition of $\left[\mathrm{NO}_{2}\right] \mathrm{BF}_{4}$ proved essential for a controlled, selective introduction of the nitro-functionality into the porphyrin, and bis- and tris-nitrated TPP products were obtained in high yields (Scheme 1). Importantly, dinitration of TPP using $\left[\mathrm{NO}_{2}\right] \mathrm{BF}_{4}$ yielded exclusively 5,10-bis- $\mathrm{NO}_{2}$-TPP (Figure 1). Furthermore, subjecting $\mathrm{NO}_{2}$-TPP and 5,10-bis- $\mathrm{NO}_{2}$-TPP to a sequential addition of $\left[\mathrm{NO}_{2}\right] \mathrm{BF}_{4}$ produced $5,10-$ bis- $\mathrm{NO}_{2}$ TPP and 5,10,15-tris- $\mathrm{NO}_{2}$-TPP, respectively, as judged by TLC monitoring.

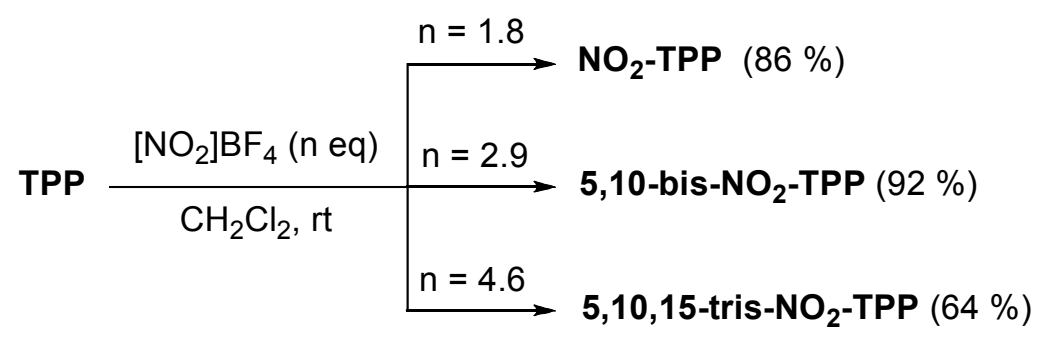

Scheme 1. Nitration of porphyrins using $\left[\mathrm{NO}_{2}\right] \mathrm{BF}_{4} /$ sulfolane solution.

Regretfully, our attempts to produce 5,10,15,20-tetrakis-NO $\mathrm{NO}_{2}$-TPP (Figure 1) using TPP as the starting material failed as a complex mixture of products was obtained. In this light, we explored the nitration of 5,10,15-tris- $\mathrm{NO}_{2}-\mathrm{TPP}$. Sequential addition of $\left[\mathrm{NO}_{2}\right] \mathrm{BF}_{4}$ of up to 6 equivalents to a dichloromethane solution of 5,10,15-tris- $\mathrm{NO}_{2}$-TPP did not result in the desired nitration product and unreacted starting material was recovered. Upon further increase of the amount of $\left[\mathrm{NO}_{2}\right] \mathrm{BF}_{4}$ (up to 10 equivalents) we observed a formation of a complex mixture of products as determined by TLC and NMR analyses.

As an alternative route to obtain 5,10,15,20-tetrakis-TPP, we probed the effect of various additives on the nitration of TPP with $\left[\mathrm{NO}_{2}\right] \mathrm{BF}_{4}$. Nitration of porphyrins in the presence of TFA was shown to be extremely facile. ${ }^{7}$ Therefore, we probed the ability of TFA/ $\left[\mathrm{NO}_{2}\right] \mathrm{BF}_{4}$ system to aid in the formation of 5,10,15,20-tetrakis- $\mathrm{NO}_{2}$-TPP. Addition of equimolar $\left[\mathrm{NO}_{2}\right] \mathrm{BF}_{4}$ to a mixture of TPP and TFA proved to be highly reactive as mixtures of $\mathrm{NO}_{2}$-TPP, 5, 10-bis- $\mathrm{NO}_{2}-$ TPP and 5,15-bis- $\mathrm{NO}_{2}$-TPP along with some unreacted TPP were obtained. Our attempts to take advantage of the high reactivity of this system to produce 5,10,15,20-tetrakis- $\mathrm{NO}_{2}$-TPP were unsuccessful, and complex mixtures were obtained once the TPP/TFA mixtures were exposed to an excess of $\left[\mathrm{NO}_{2}\right] \mathrm{BF}_{4}$. Conducting the reactions at lower temperature as well as using various ratios of TFA $/ \mathrm{CH}_{2} \mathrm{Cl}_{2}$ as the reaction mixture did not provide any improvement. Furthermore, substituting TFA with a less reactive glacial acetic acid appeared to be much inferior, as primarily unreacted TPP was observed, with small amounts of $\mathrm{NO}_{2}-\mathrm{TPP}$ and 5,10-bis- $\mathrm{NO}_{2}-\mathrm{TPP}$ observed by TLC even after the addition of 5 equivalents of $\left[\mathrm{NO}_{2}\right] \mathrm{BF}_{4}$. 
Although nitration of TPP using $\left[\mathrm{NO}_{2}\right] \mathrm{BF}_{4}$ in sulfolane is attractive, removal of sulfolane presented a concern. For small-scale reactions ( $c a .50 \mathrm{mg}$ of TPP) a flash chromatography $\left(\mathrm{CH}_{2} \mathrm{Cl}_{2}\right.$ /silica gel) was found to be convenient in removing sulfolane. However, in case of 5,10,15-tris- $\mathrm{NO}_{2}$-TPP synthesis, as well as large scale ( $c a .0 .9-1.0 \mathrm{~g}$ of TPP) the amount of sulfolane demanded repetitive chromatographic purification. In this light, we searched for a nonchromatographic approach. It appeared that dissolving a crude mixture, i.e., nitrated TPP and sulfolane, in hot acetone followed by addition of excess of water and subsequent cooling was efficient in yielding pure nitrated porphyrins. Importantly, both isolation protocols provided virtually the same yields, i.e., $82 \%$ for small-scale reactions, which utilized flash chromatography, and $86 \%$ for large-scale reactions, which utilized the precipitation-based procedure. All prepared here nitro-containing TPP (Scheme 1) were successfully reduced to the corresponding amines, following a literature procedure. ${ }^{7}$

Metalloporphyrins, namely $\mathrm{Cu}$-TPP and $\mathrm{Zn}$-TPP, did not undergo nitration under these conditions, and decomposition of the porphyrin's structure was detected even upon addition of 1 equivalent of $\left[\mathrm{NO}_{2}\right] \mathrm{BF}_{4}$. We also investigated the effect of solvents and solvent mixtures on the $\left[\mathrm{NO}_{2}\right] \mathrm{BF}_{4}$ nitration of TPP. $\mathrm{CH}_{2} \mathrm{Cl}_{2}$ proved to be the only efficient solvent. The use of mixtures of $\mathrm{CH}_{2} \mathrm{Cl}_{2}$ and $\mathrm{CH}_{3} \mathrm{CN}$ or $\mathrm{Et}_{2} \mathrm{O}$ proved inefficient, as no nitration product was detected, and TPP was recovered unchanged even upon addition of 4 equivalents of $\left[\mathrm{NO}_{2}\right] \mathrm{BF}_{4}$.

In order to gain some insight on the mechanism of $\left[\mathrm{NO}_{2}\right] \mathrm{BF}_{4}$ nitration, we examined the effect of the sequential $\left[\mathrm{NO}_{2}\right] \mathrm{BF}_{4}$ addition to TPP using NMR spectroscopy (Scheme 2).

TPP exhibits a typical singlet at $-2.8 \mathrm{ppm}$, corresponding to two N-Hs, and a set of three resonances in the aromatic region (Scheme 2). Upon addition of 1 equivalent of $\left[\mathrm{NO}_{2}\right] \mathrm{BF}_{4}$ the NH sharp peak disappeared, and two broader peaks were detected between $c a$. -1 and -3 ppm, and the aromatic region also underwent a dramatic change as a new set of peaks was noted: TPP's multiplets at 7.8 and $8.2 \mathrm{ppm}$ partially shifted downfield to 8.0 and $8.6 \mathrm{ppm}$, respectively; whereas the singlet at $8.9 \mathrm{ppm}$ shifted upfield to $8.7 \mathrm{ppm}$. Notably, a change from a red solution (TPP in dichloromethane) to a green solution upon addition of $\left[\mathrm{NO}_{2}\right] \mathrm{BF}_{4}$ was observed. This color change is similar to that observed upon protonation of TPP by TFA or any other strong acid. Furthermore, the changes of the aromatic resonances, which were observed upon addition of 1 equivalent of $\left[\mathrm{NO}_{2}\right] \mathrm{BF}_{4}$ to TPP, were virtually identical to those observed upon addition of 1 equivalent of TFA to TPP. Also, ${ }^{19} \mathrm{~F}$ NMR exhibited a sharp singlet at $-156.2 \mathrm{ppm}$. Both ${ }^{1} \mathrm{H}$ and ${ }^{19} \mathrm{~F}$ NMR spectra had remained unchanged over a 1.5 -hour period. Formation of $\mathrm{NO}_{2}-\mathrm{TPP}_{\text {was }}$ not observed at this stage, as judged by TLC analysis performed during the preparative procedure, which arguably suggested that a mixture of $\mathrm{NO}_{2}{ }^{+}$-coordinated and free TPP was obtained at this stage.

It should be pointed out that ${ }^{19} \mathrm{~F}$ NMR of a $\left[\mathrm{NO}_{2}\right] \mathrm{BF}_{4}$-sulfolane solution in $\mathrm{CDCl}_{3}(22 \mathrm{mM})$ showed a broad signal at $-150 \mathrm{ppm}$, whereas a more concentrated solution, i.e., 2.2 M, exhibited a multiplet at $c a$. $-150 \mathrm{ppm}$ and broad multiplet centered around $-155 \mathrm{ppm}$. The ratio between these signals depended on the concentration of the solution. 


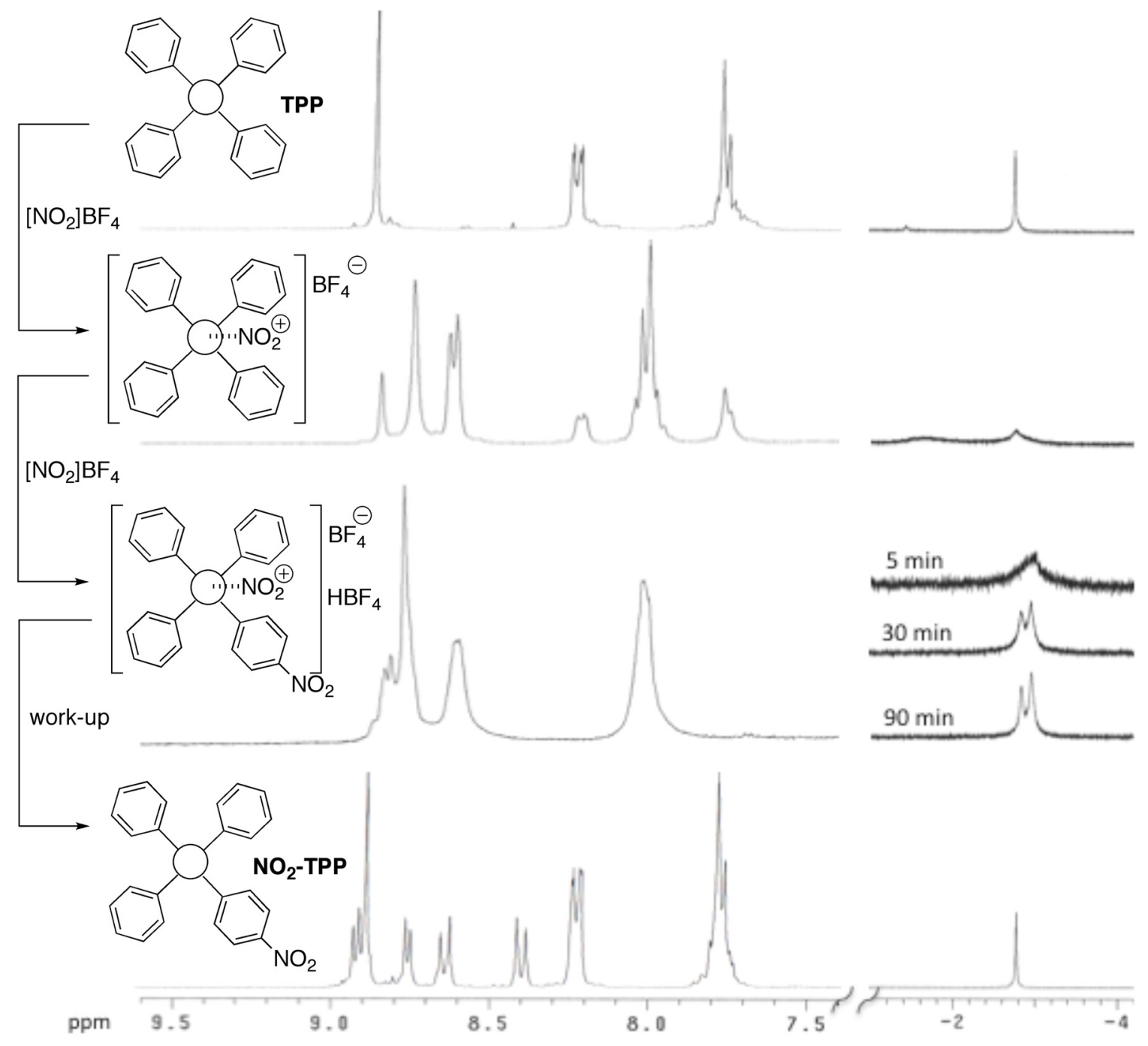

Scheme 2. NMR monitoring of $\left[\mathrm{NO}_{2}\right] \mathrm{BF}_{4}$ addition to TPP $\left(14.6 \mathrm{mM}\right.$ in $\left.\mathrm{CDCl}_{3}\right)$.

Subsequent addition of another equivalent of $\left[\mathrm{NO}_{2}\right] \mathrm{BF}_{4}$ resulted in a rapid change from green to red to brown and back to green solution. According to NMR spectra any noncoordinated TPP was removed (Scheme 2) and distinct changes in the NH-resonances were observed. Arguably, the broadening of the aromatic resonances might stem from the enhanced interactions between the porphyrins and coordinated nitronium ion. ${ }^{19} \mathrm{~F}$ NMR showed two broad multiplets at -150.5 and $-155.2 \mathrm{ppm}$ in a 1 to 10 ratio, respectively. Both chemical shifts and the ratio of ${ }^{19} \mathrm{~F}$ NMR resonances appeared to be time independent.

We examined the effect of sulfolane, TPP concentration and varying concentrations of TFA on the behavior of aromatic resonances of TPP, and in all cases we observed no significant changes, neither in chemical shift nor broadening of the signals. Arguably, the observed broadening and shifting of the NMR signals of TPP upon the addition of $\left[\mathrm{NO}_{2}\right] \mathrm{BF}_{4}$ was due to a TPP- $-\mathrm{NO}_{2}{ }^{+}$coordination complex, which might involve stacked structure, with the nitronium ion 
being located in between the porphyrins, which would provide some extra stabilization of the positive charge.

The NMR changes (Scheme 2) were in accordance with TLC monitoring of the preparative reactions, which indicated that all TPP was quantitatively converted into the mononitrated porphyrin. Further monitoring of the $\left[\mathrm{NO}_{2}\right] \mathrm{BF}_{4}$ addition was precluded by the increasing amounts of sulfolane. However, when nitration of $\mathrm{NO}_{2}-\mathrm{TPP}$ with $\left[\mathrm{NO}_{2}\right] \mathrm{BF}_{4}$ was monitored by NMR under identical conditions described for nitration of TPP, we observed qualitatively similar changes of all resonances, both ${ }^{1} \mathrm{H}$ and ${ }^{19} \mathrm{~F}$. Overall, the NMR results suggested that the nitration of TPP using $\left[\mathrm{NO}_{2}\right] \mathrm{BF}_{4}$ proceeded via a nitronium coordination - nitration sequence in a highly controllable manner.

\section{Conclusions}

We have identified $\left[\mathrm{NO}_{2}\right] \mathrm{BF}_{4}$ as a convenient reagent for selective and controllable nitration of TPP under mild conditions. Consecutive incorporation of up to three nitro-groups is readily achieved, and the corresponding nitro-containing porphyrins can be isolated using a chromatography-free procedure in high yields.

\section{Experimental Section}

General. All reagents and solvents were from commercial sources (Sigma-Aldrich, Acros or Alfa Aesar) and were used as received. TPP was purchased from Frontier Scientific, Inc. Reactions were monitored by TLC (silica gel 60 F254). Column chromatography was performed using silica gel (230-400 mesh). ${ }^{1} \mathrm{H}$ NMR spectra were recorded on a Varian $(300 \mathrm{MHz})$ spectrometer. The chemical shifts are reported in $\mathrm{ppm}(\delta)$ downfield from tetramethylsilane in $\mathrm{CDCl}_{3}$.

\section{Synthesis of $\mathrm{NO}_{2}$-TPP}

Solution of TPP $(59 \mathrm{mg}, 0.096 \mathrm{mmol})$ in $\mathrm{CH}_{2} \mathrm{Cl}_{2}(13.5 \mathrm{ml})$ was purged with $\mathrm{N}_{2}$ for 10 min at room temperature. $\left[\mathrm{NO}_{2}\right] \mathrm{BF}_{4}(0.175 \mathrm{ml}, 0.09 \mathrm{mmol} ; 0.5 \mathrm{M}$ in sulfolane $)$ was added dropwise over a period of $10 \mathrm{~min}$. The mixture was stirred for $30 \mathrm{~min}$, and another portion of $\left[\mathrm{NO}_{2}\right] \mathrm{BF}_{4}$ $(0.175 \mathrm{ml}, 0.09 \mathrm{mmol} ; 0.5 \mathrm{M}$ in sulfolane) was added dropwise. The mixture was stirred for 10 min and water $(100 \mathrm{ml})$ was added. The organic layer was washed with water $(2 \times 100 \mathrm{ml})$, dried $\left(\mathrm{MgSO}_{4}\right)$ and volatiles removed in vacuo. The residue was flash chromatographed using dichloromethane as eluent to give $52 \mathrm{mg}$ (82\% yield) of $\mathrm{NO}_{2}$-TPP, those spectral properties matched the published data. ${ }^{6 \mathrm{a}} \mathrm{H}$ NMR $\left(300 \mathrm{MHz}, \mathrm{CDCl}_{3}\right): \delta=8.90(\mathrm{~d}, J=4.8 \mathrm{~Hz}, 2 \mathrm{H}), 8.88(\mathrm{~s}$, $4 \mathrm{H}), 8.74$ (d, $J=4.8 \mathrm{~Hz}, 2 \mathrm{H}), 8.63$ (d, $J=8.8 \mathrm{~Hz}, 2 \mathrm{H}), 8.39$ (d, $J=8.8 \mathrm{~Hz}, 2 \mathrm{H}), 8.22(\mathrm{~m}, 6 \mathrm{H})$, $7.79(\mathrm{~m}, 9 \mathrm{H}),-2.70(\mathrm{~s}, 2 \mathrm{H})$. 
Synthesis of $\mathrm{NO}_{2}$-TPP, a scale-up procedure. Solution of TPP $(0.93 \mathrm{~g}, 1.51 \mathrm{mmol})$ in $\mathrm{CH}_{2} \mathrm{Cl}_{2}$ $(180 \mathrm{ml})$ was purged with $\mathrm{N}_{2}$ for $10 \mathrm{~min}$ at room temperature. $\left[\mathrm{NO}_{2}\right] \mathrm{BF}_{4}(2.74 \mathrm{ml}, 1.37 \mathrm{mmol}$; $0.5 \mathrm{M}$ in sulfolane) was added dropwise over a period of $30 \mathrm{~min}$ (slow addition was found to be crucial for the mononitration; faster addition rates tended to produce mixtures of $\mathrm{NO}_{2}$-TPP and 5,10-bis- $\mathrm{NO}_{2}$-TPP). The mixture was stirred for $30 \mathrm{~min}$, and another portion of $\left[\mathrm{NO}_{2}\right] \mathrm{BF}_{4}(2.74$ $\mathrm{ml}, 1.37 \mathrm{mmol} ; 0.5 \mathrm{M}$ in sulfolane) was added dropwise over a period of $30 \mathrm{~min}$. At this time, TLC showed small amount of unreacted TPP, hence $\left[\mathrm{NO}_{2}\right] \mathrm{BF}_{4}(0.5 \mathrm{ml}, 0.25 \mathrm{mmol} ; 0.5 \mathrm{M}$ in sulfolane) was added dropwise over $c a .5 \mathrm{~min}$. The mixture was stirred for $15 \mathrm{~min}$, followed by the dropwise over $c a$. $5 \mathrm{~min}$ addition of $\left[\mathrm{NO}_{2}\right] \mathrm{BF}_{4}(0.5 \mathrm{ml}, 0.25 \mathrm{mmol} ; 0.5 \mathrm{M}$ in sulfolane $)$ and the mixture was allowed to stir for $20 \mathrm{~min}$. TLC indicated a complete consumption of TPP. Next, the reaction mixture was extracted with water $(2 \times 200 \mathrm{ml})$, and the volatiles removed in vacuo. The residue was dissolved in acetone $(10 \mathrm{ml})$ and added to ice/water mixture $(c a .800 \mathrm{ml})$. The formed precipitate was collected by filtration, dissolved in $\mathrm{CH}_{2} \mathrm{Cl}_{2}$ (ca. $50 \mathrm{ml}$ ), dried $\left(\mathrm{MgSO}_{4}\right)$ and volatiles removed in vacuo to give $0.94 \mathrm{~g}$ (94\% yield) of $\mathrm{NO}_{2}$-TPP.

\section{Synthesis of 5,10-bis- $\mathrm{NO}_{2}$-TPP}

Solution TPP (64 mg, $0.10 \mathrm{mmol})$ in $\mathrm{CH}_{2} \mathrm{Cl}_{2}(13.5 \mathrm{ml})$ was purged with $\mathrm{N}_{2}$ for $10 \mathrm{~min}$ at room temperature. $\left[\mathrm{NO}_{2}\right] \mathrm{BF}_{4}(0.19 \mathrm{ml}, 0.095 \mathrm{mmol} ; 0.5 \mathrm{M}$ in sulfolane $)$ was added dropwise over a period of $10 \mathrm{~min}$, and stirring continued for $30 \mathrm{~min}$. The addition was repeated in the same manner until a total of 2.9 equivalents of $\left[\mathrm{NO}_{2}\right] \mathrm{BF}_{4}$ were added. Following the addition of dichloromethane $(100 \mathrm{ml})$ and water $(100 \mathrm{ml})$, the organic layer was washed with water $(2 \times 100$ $\mathrm{ml})$, dried $\left(\mathrm{MgSO}_{4}\right)$ and volatiles removed in vacuo. The residue was dissolved in acetone (3.0 $\mathrm{ml})$ and water was added until cloudiness $(\mathrm{ca} .50 \mathrm{ml})$ was observed. The mixture was placed on ice and the precipitate was collected by filtration to give $65 \mathrm{mg}$ ( $92 \%$ yield) of 5,10-bis- $\mathrm{NO}_{2}$ TPP, those spectral properties matched the published data. ${ }^{6 \mathrm{~b}}{ }^{1} \mathrm{H}$ NMR $\left(300 \mathrm{MHz}, \mathrm{CDCl}_{3}\right): \delta=$ $8.93(\mathrm{~d}, J=4.9 \mathrm{~Hz}, 2 \mathrm{H}), 8.79$ (s, 2H), 8.75 (s, 2H), 8.75 (d, $J=4.9 \mathrm{~Hz}, 2 \mathrm{H}), 8.62$ (d, $J=8.3 \mathrm{~Hz}$, $4 \mathrm{H}), 8.38(\mathrm{~d}, J=8.3 \mathrm{~Hz}, 4 \mathrm{H}), 8.23(\mathrm{~m}, 4 \mathrm{H}), 7.80(\mathrm{~m}, 6 \mathrm{H}),-2.79(\mathrm{~s}, 2 \mathrm{H})$.

\section{Synthesis of 5,10,15-tris- $\mathrm{NO}_{2}$-TPP}

Solution TPP (50 mg, $0.081 \mathrm{mmol})$ in $\mathrm{CH}_{2} \mathrm{Cl}_{2}(10 \mathrm{ml})$ was purged with $\mathrm{N}_{2}$ for $10 \mathrm{~min}$ at room temperature. $\left[\mathrm{NO}_{2}\right] \mathrm{BF}_{4}(0.15 \mathrm{ml}, 0.075 \mathrm{mmol} ; 0.5 \mathrm{M}$ in sulfolane $)$ was added dropwise over a period of $10 \mathrm{~min}$, and stirring continued for $30 \mathrm{~min}$. The addition was repeated in the same manner until a total of 4.6 equivalents of $\left[\mathrm{NO}_{2}\right] \mathrm{BF}_{4}$ were added. Following the addition of dichloromethane $(100 \mathrm{ml})$ and precipitate was collected by filtration to give $39 \mathrm{mg}$ (64\% yield) of 5,10,15-tris- $\mathrm{NO}_{2}$-TPP, those spectral properties matched the published data. ${ }^{\text {a }}{ }^{1} \mathrm{H}$ NMR $(300$ $\left.\mathrm{MHz}, \mathrm{CDCl}_{3}\right): \delta=8.93(\mathrm{~d}, J=4.9 \mathrm{~Hz}, 2 \mathrm{H}), 8.81(\mathrm{~m}, 6 \mathrm{H}), 8.66(\mathrm{~d}, J=8.8 \mathrm{~Hz}, 6 \mathrm{H}), 8.40(\mathrm{~d}, J=$ $8.5 \mathrm{~Hz}, 6 \mathrm{H}), 8.21(\mathrm{~m}, 2 \mathrm{H}), 7.80(\mathrm{~m}, 3 \mathrm{H}),-2.80(\mathrm{~s}, 2 \mathrm{H})$. 


\section{NMR study}

TPP (4.5 mg, $7.3 \mu \mathrm{mol}$ ) was charged into an NMR tube, the tube was sealed, evacuated and back-filled with $\mathrm{N}_{2}$. $\mathrm{CDCl}_{3}(0.5 \mathrm{ml})$ was added, followed by the addition of the appropriate amount of $\left[\mathrm{NO}_{2}\right] \mathrm{BF}_{4}$ at room temperature with gentle shaking. Periodically, the NMR spectra were acquired at room temperature.

\section{Acknowledgements}

This work was supported in part by the donors of the ACS-Petroleum Research Fund (47965-G7) and TCU-RCAF (A6347). NWS acknowledges the ACS Division of Medicinal Chemistry for a predoctoral fellowship sponsored by Wyeth.

\section{References}

1. (a) Aratani, N.; Kim, D.; A. Osuka, Acc. Chem. Res. 2009, 42, 1922. (b) O'Connor, A. E.; Gallagher, W. M.; Byrne, A. T. Photochem. Photobiol. 2009, 85, 1053. (c) Che, C-M.; Huang, J-S. Chem. Commun. 2009, 3996. (c) Tsuda, A. Bull. Chem. Soc. Jpn. 2009, 82, 11. (d) D’Souza, F.; Ito, O. Chem. Commun. 2009, 4913. (e) Aratani, N.; Kim. D.; Osuka, A. Chem. Asian J. 2009, 4, 1172.

2. (a) Lindsey, J. S. Acc. Chem. Res. 2010, 43, 300. (b) Vicente, M. G. H.; Smith, K. M. Curr. Org. Chem. 2000, 4, 139. (c) Lash, T. D. Chem. Eur. J. 1996, 2, 1197; (d) Meunier, B. Chem. Rev. 1992, 92, 1411.

3. (a) Mathew, S.; Johnston, M. R. Chem. Eur. J. 2009, 15, 248. (b) Rai, S.; Ravikanth, M. J. Org. Chem. 2008, 73, 8364. (c) Matthews, S. E.; Pouton, C. W.; Threadhill, M. D. New J. Chem. 1999, 23, 1087.

4. (a) Palacio, M.; Juillard, A.; Leduc, P.; Battioni, P.; Mansuy, D. J. Organometal. Chem. 2002, 643-644, 522. (b) Palacio, M.; Mansuy-Mouries, V.; Loire, G.; Le Barch-Ozette, K.; Leduc, P.; Barkigia, K. M.; Fajer, J.; Battioni, P.; Mansuy, D. Chem. Commun. 2000, 1907. (c) Bartoli, J-F.; Mouries-Mansuy, V.; Le Barch-Ozette, K.; Palacio, M.; Battioni, P.; Mansuy, D. Chem. Commun. 2000, 827. (d) Suslik, K. S.; Chen, C-T.; Meredith, G. R.; Cheng, L-T. J. Am. Chem. Soc. 1992, 114, 6928.

5. (a) Wyrebek, P.; Ostrowski, S. J. Porphyr. Phthalocya. 2007, 11, 822. (b) Wickramsinghe, A.; Jaquinod, L.; Nurco, D. J.; Smith, K. M. Tetrahedron 2001, 57, 4261. (c) Ali, H.; Van Lier, J. E. Tetrahedron Lett. 1991, 32, 5015. (d) Baldwin, J. E.; Crossley, M. J.; DeBernardis, J. Tetrahedron 1981, 38, 685.

6. (a) Kruper, Jr. W. J.; Chamberlin, T. A.; Kochanny, M. J. Org. Chem. 1989, 54, 2753. (b) Ostrowski, S.; Lopuszynska, B. Synth. Commun. 2003, 33, 4101. (c) Ostrowski, S.; Mikus, A.; Lopuszynska, B. Tetrahedron 2004, 60, 11951. 
7. (a) Luguya, R.; Jaquinod, L.; Fronczek, F. R.; Vicente, M. C. H.; Smith, K. M. Tetrahedron 2004, 60, 2757. (b) Weimin, S.; Gen, Z.; Guifu, D.; Yunxiao, Z.; Jun, Z.; Jinchao, T. Bioorg. Med. Chem. 2008, 16, 5665.

8. Esteves, P. M.; Walkimar de Carneiro, J.; Cardoso, S. P.; Barbosa, A. G. H.; Laali, K. K.; Rasul, G.; Prakash, G. K. S.; Olah, G. A. J. Am. Chem. Soc. 2003, 125, 4836.

9. Bonnett, R.; Stephenson, G. F. J. Org. Chem. 1965, 30, 2791.

10. Cavaleiro, J. A. S.; Neves, M. G. P. M. S.; Hewlins, M. J. E.; Jackson, A. H. J. Chem. Soc., Perkin 1 1986, 575. 